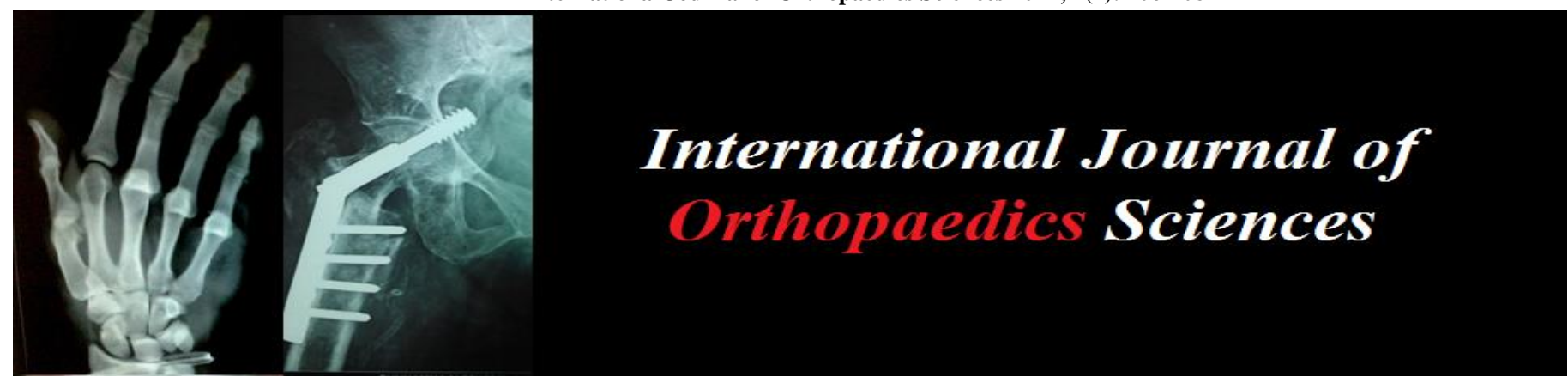

E-ISSN: 2395-1958

P-ISSN: 2706-6630

IJOS 2021; 7(4): 406-408

(C) 2021 IJOS

www.orthopaper.com

Received: 10-08-2021

Accepted: 12-09-2021

Dr. Jyothiprasanth M Consultant Orthopaedics,

Gimcare Hospital, Kannur,

Kerala, India

Dr. Palanisamy Jeyavenkatesh Consultant Orthopaedics, Janan Hospital, Tiruvallur, Tamilnadu, India

\section{Dr. Akhil K Thomas}

Associate Consultant

Orthopaedics, Gimcare Hospital,

Kannur, Kerala, India

Dr. Sarang $\mathbf{P}$

Pharm D, Department of

Orthopaedic, Gimcare Hospital,

Kannur, Kerala, India

Corresponding Author:

Dr. Sarang $P$

Pharm D, Department of

Orthopaedics, Gimcare Hospital,

Kannur, Kerala, India

\section{Longitudinal tear of peroneus brevis tendon: An unusual cause for ankle pain: A case report}

\author{
Dr. Jyothiprasanth M, Dr. Palanisamy Jeyavenkatesh, Dr. Akhil K \\ Thomas and Dr. Sarang $P$
}

DOI: https://doi.org/10.22271/ortho.2021.v7.i4f.2909

\begin{abstract}
Introduction: One of the rare causes of chronic ankle pain is a longitudinal tear of peroneus brevis tendon. Peroneus Brevis (PB) tears are thought to occur from both trauma and chronic instability, with and without subluxation former being more common. We report a case of chronic lateral ankle pain due to longitudinal tear of the peroneus brevis tendon without subluxation. Case report: A 51 years female, presented with pain and swelling behind the lateral malleolus on the left side. She had a twisting injury to the ankle before six months. The patient had pain with active resistance to eversion and single- legged standing. Magnetic Resonance image showed an irregularity at PB tendon and excessive fluid inside the synovial sheath, consistent with a partial-thickness tear. Surgical exploration of the peroneal tendon was performed. A longitudinal split of the peroneus brevis tendon about $3 \mathrm{~cm}$ long was noted at the level of retrofibular groove, the peroneus longus was intact and neither of the tendons was subluxated. The one part of the torn PB tendon which was frayed was trimmed distally and sutured to the main tendon using an absorbable suture. The lax superior peroneal retinaculum was plicated and fixed to the fibula using a suture anchor. The bony irregularities in the posterior aspect of lateral malleolus were smoothened to prevent further attrition tear. At one year follow up, the patient had no residual symptoms. Conclusion: Injury to the peroneal tendons is a frequently overlooked cause of persistent lateral ankle pain after trauma. High degree of clinical suspicion is important to diagnose the injuries. MRI serves as the key diagnostic tool. These tendon injuries need to be managed based on the extent and quality of the tears. Associated pathologies have to be addressed to prevent recurrence.
\end{abstract}

Keywords: ankle sprain, sports injury, tendon tear, peroneus brevis, ankle pain

\section{Introduction}

Longitudinal tear of Peroneus Brevis tendon is a rare cause of chronic ankle pain [1, 2]. Peroneus Brevis (PB) tears are thought to occur from both trauma and chronic instability, with and without subluxation former being more common ${ }^{[3]}$. We report a case of chronic lateral ankle pain due to longitudinal tear of the peroneus brevis tendon without subluxation.

\section{Case report}

A 51 years female, a manual labourer, presented with longitudinal swelling behind the lateral malleolus on the left side (Figure 1). There were pain and discomfort on walking and climbing stairs. She was symptomatic for about six months when she sustained a trivial ankle injury. There was no symptomatic relief despite the conservative treatments of rest, ice fomentation, compression bandage application and physiotherapy. Clinically, the swelling was present in the posterolateral aspect along the peroneal tendons measuring 7 centimeters $(\mathrm{cm})$ in length and about $3 \mathrm{~cm}$ in width. The normal retromalleolar hollowness was obliterated and swelling extended distal and anterior to tip of fibula. Tenderness was elicited over the swelling and along the lateral aspect of the leg. The patient had pain with active resistance to eversion, and with single-legged weight bearing. There was no popping or snapping of tendons that excludes the diagnosis of peroneal tendon subluxation. Plain radiograph did not show any bony lesion or intraarticular pathology in the ankle. T2-weighted Magnetic Resonance image at the level of the hindfoot showed an irregularity at the posterior aspect of the PB tendon and excessive fluid inside the synovial sheath (arrow), consistent with a partial-thickness tear (figure 2). 
Surgical exploration of the peroneal tendon was performed. Curvilinear lateral approach was made over peroneal tendons. The superior peroneal retinaculaum (SPR) found to be stretched and elongated. Peroneal tendon sheath was incised longitudinally $3 \mathrm{~mm}$ posterior to the posterior border of the fibula. Thickening of the synovial sheath and effusion was noted. A longitudinal split of the peroneus brevis tendon about $3 \mathrm{~cm}$ long was noted at the level of retro fibular groove (Figure 3), the peroneus longus was intact and neither of the peroneal tendons was subluxated. The one part of the torn PB tendon which was frayed was trimmed distally and sutured to the main tendon using an absorbable suture. The retrofibular groove was normal except for rough bony edge which could have led to tear of the PB tendon. These bony irregularities in the posterior aspect of fibula were smoothened and the lax SPR was tightened by plication of retinaculum and reattaching the SPR to the fibula using a suture anchor (Figure 4). The excursion of tendons was normal and there was no subluxation intraoperatively. Post operatively the patient was kept on non weight bearing below knee cast in neutral position for three weeks. Then gradual mobilization of ankle was allowed. Gradual return to work was permitted three months after surgery. At one year follow up, patient had no residual symptoms.

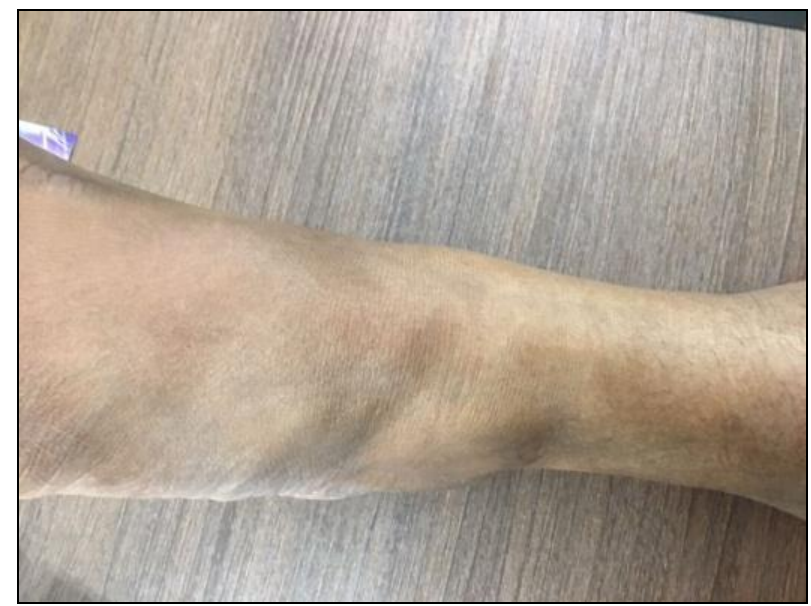

Fig 1: Clinical picture showing swelling along the length of peronei behind the lateral malleolus.

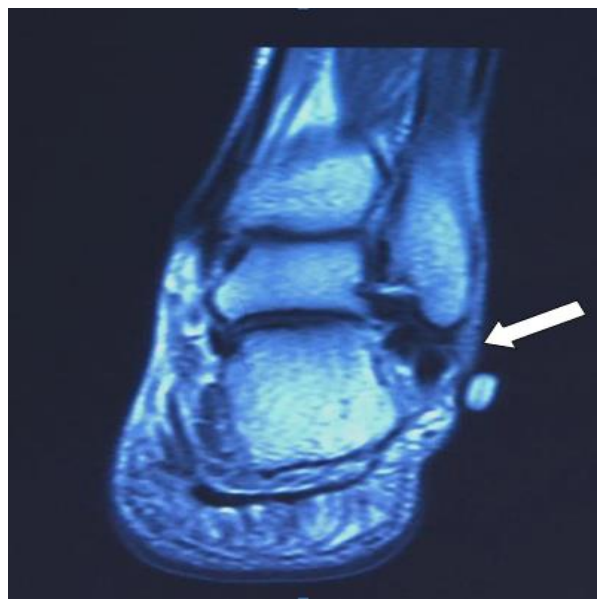

Fig 2: MRI showing coronal section through ankle joint, marked edema and fluid collection is clearly evident surrounding peroneal tendons.

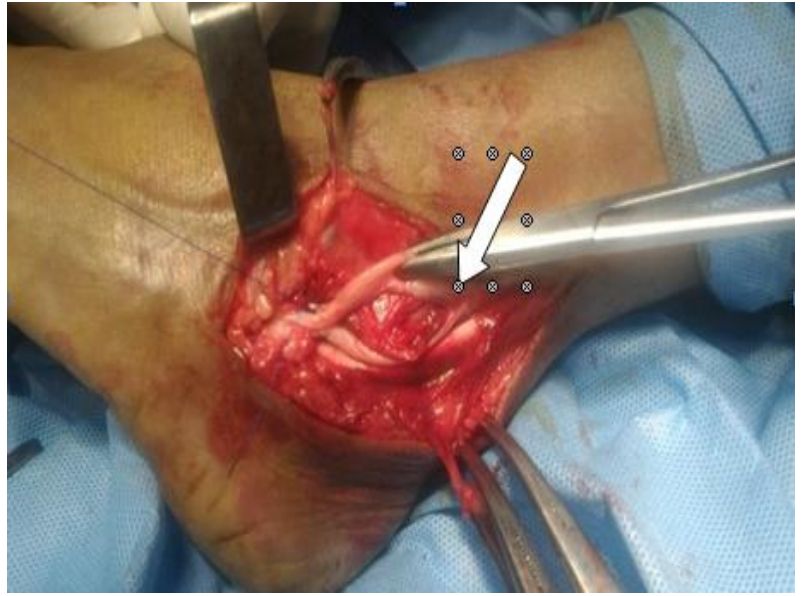

Fig 3: Intraop picture showing Peroneus brevis tear (arrow at the bifurcation). Intact Peroneus longus is seen posterior to PB.

\section{Discussion}

Peroneus brevis tendon is anterior to the peroneus longus tendon at the level of the ankle joint and, therefore, is closer to the lateral malleolus. PB tears occur due to repeated mechanical abrasion of the tendon against the posterolateral lip of the fibula. The usual presentation is a longitudinal split in the tendon, occasionally a 'bucket handle' type of tear can occur but a complete rupture of the tendon is rare ${ }^{[4]}$. The true incidence of peroneus brevis tears is not known, based on cadaveric studies the estimates range from $11-37 \%$ in general population. The Longitudinal tears often centered over the distal tip of fibula in the fibular groove and averaged about $1.9 \mathrm{~cm}$ (range 1-4), in our patient the tear was $3 \mathrm{~cm}$ long ${ }^{[3]}$. The rationale of treatment is to preserve as much as tendon as possible and to treat predisposing pathologies concomitantly. If less than $50 \%$ of the tendon thickness is involved as in our case, the affected part of debrided and tabularized ${ }^{5}$. Predisposing factors such as rough posterior surface of fibula, a low lying muscle belly, peroneal subluxation or hypertrophic peroneal tubercle have to be addressed in order to prevent recurrent tearing, pain and dysfunction. We encountered an uneven surface of the distal fibula which was smoothened using bone rasp. Superior peroneal retinaculum (SPR) is another structure which plays a crucial role in maintaining the integrity of the peroneal tendons. SPR acts as a restraint to the peroneal tendons and an inversion injury can cause attenuation and laxity of the retinaculum. This laxity allows excessive excursion of the tendons and lead to mechanical attrition of the peroneus brevis against posterior lip of fibula ${ }^{[6]}$. In the reported case the SPR was lax and spacious so it was imbricated and attached to the fibula using suture anchors to obliterate the excess space. 


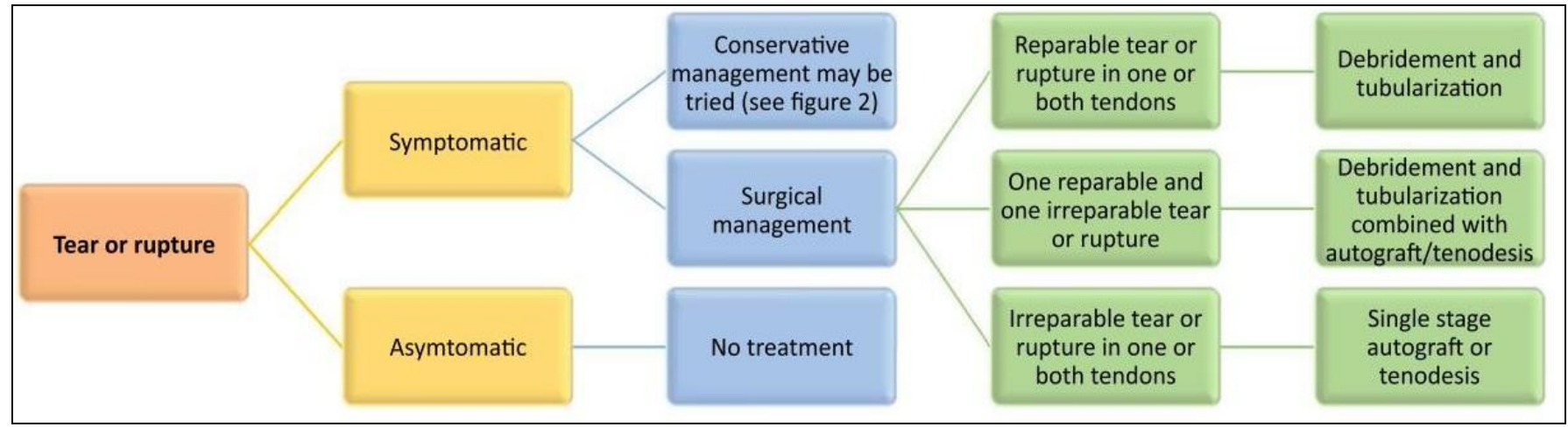

Fig 4: Treatment Algorithm for peroneus tendon tears.

\section{Conclusion}

Injury to the peroneal tendons is a frequently overlooked cause of persistent lateral ankle pain after trauma ${ }^{[7]}$. High degree of clinical suspicion is important to diagnose the injuries. MRI serves as the key diagnostic tool. These tendon injuries needs to be managed based on the extent and quality of the tears. Associated pathologies have to be addressed to prevent recurrence.

\section{References}

1. Danna NR, Brodsky JW. Diagnosis and Operative Treatment of Peroneal Tendon Tears. Foot Ankle Orthop 2020;5(2):2473011420910407.

2. Walt J, Massey P. Peroneal Tendon Syndromes. In: StatPearls [Internet]. Treasure Island (FL): Stat Pearls Publishing; 2020 [cited 2021 Jan 1]. Available from: http://www.ncbi.nlm.nih.gov/books/NBK544354/

3. Selmani E, Gjata V, Gjika E. Current concepts review: peroneal tendon disorders. Foot Ankle Int 2006;27(3):221-8.

4. Clarke HD, Kitaoka HB, Ehman RL. Peroneal tendon injuries. Foot Ankle Int 1998;19(5):280-8.

5. van Dijk PA, Miller D, Calder J, DiGiovanni CW, Kennedy JG, Kerkhoffs GM, et al. The ESSKA-AFAS international consensus statement on peroneal tendon pathologies. Knee Surg Sports Traumatol Arthrosc Off J ESSKA 2018;26(10):3096-107.

6. Squires N, Myerson MS, Gamba C. Surgical treatment of peroneal tendon tears. Foot Ankle Clin 2007;12(4):67595, vii.

7. Koh D, Liow L, Cheah J, Koo K. Peroneus longus tendon rupture: A case report. World J Orthop 2019;10(1):45-53. 